\title{
Ultrastructural investigation of the nuchal organs of Pygospio elegans (Polychaeta). I. Larval nuchal organs
}

\author{
U. Schlötzer-Schrehardt \\ Institut für Zoologie der Universität Erlangen-Nürnberg, \\ Staudtstraße 5, D-8520 Erlangen, FRG
}

\begin{abstract}
The structural differentiation of the nuchal organs during the post-embryonic development of Pygospio elegans is described. The sensory organs are composed of two cell types: ciliated cells and bipolar primary sensory cells, constituting the nuchal ganglion, which is associated with both the sensory epithelium and the brain. Since the sensory neurons are largely integrated into posterolateral parts of the cerebral ganglion, the nuchal organs are primary presegmental structures. The microvilli of the ciliated cells form a cover over the cuticle with a presumed protective function. An extracellular space extends between cuticle and sensory epithelium. The distal dendrites of the sensory cells terminate in sensory bulbs, bearing one modified sensory cilium each that projects into the olfactory chamber, embedded within the secretion of the ciliated cells. During development, the nuchal organs increase in size. This is accompanied by a shift in position, an expansion of the sensory area, and secretory activity of the ciliated cells. The nuchal ganglion differentiates into three nuchal centres forming three distinct sensory areas around the ciliated region. Each nuchal complex reveals two short nuchal nerves comprising the sensory axons, which enter the posterior circumesophageal connective. The sensory cells lying in the brain exhibit neurosecretory activity; the sensory cilia enlarge their surface area by dilating and branching. Nuchal organs accomplish the basic structural adaptions of chemoreceptors and show structural analogies to arthropod olfactory sensilla; thus, there is every reason to suppose chemoreceptor function.
\end{abstract}

\section{INTRODUCTION}

Polychaete nuchal organs are mostly paired, epidermal sensory structures, located on the dorsal side of the prostomium or peristomium. Based on histological and positional criteria, they are supposed to have chemoreceptor function (Rullier, 1950, 1951; Bullock \& Horridge, 1965), playing a role in food selection or mating (Söderström, 1920, 1930). Clear physiological evidence, however, is still lacking. According to Rullier (1951) and Clark (1969), nuchal organs have combined sensory and secretory functions. Their morphological diversity comprises simple pits at the posterior margin of the prostomium as well as complex folded lobes covering several segments (cf. Bullock \& Horridge, 1965).

Up to now, it is not clear whether nuchal organs are prostomial or true segmental structures secondarily joined to the brain. The latter view, represented by Söderström (1920, 1930), Gustafson (1930) and Rullier (1951) is based particularly on the family Spionidae. According to Åkesson's embryological studies on Eunice kobiensis (1967a) and Lopadorhynchus (1967b), the nuchal organs develop presegmentally from dorsolateral parts of the hindbrain. In any case, however, nuchal organs are innervated from the 
posterior portion of the brain (Clark, 1969; Korn, 1982). Only few papers describe the ultrastructure of polychaete nuchal organs (Storch \& Welsch, 1969; Whittle \& Zahid, 1974; West, 1978). The investigations reveal variations concerning, in particular, the exact position of the sensory epithelium, the cellular composition, and the location of the primary sensory cells, which are either associated with the sensory epithelium or with the brain.

No attention has yet been paid to the larval nuchal organs, neither on the light- or electron-microscopical level nor to their differentiation during post-embryonic development.

Fundamentally characteristic of the polychaete family Spionidae are the extensively developed nuchal organs. This family reveals the most primitive condition: dorsal organs, considered to be homologous with the nuchal organs, extend over a number of anterior segments (Söderström, 1920, 1930; Clark, 1969). The species Pygospio elegans proves to be of special interest because of the sexually dimorphic formation of these sensory structures (Söderström, 1920, 1930).

The aim of the present study is to examine the fine structure of the nuchal organs of $P$. elegans and their relation to the central nervous system. Part I concerns the ultrastructure, the innervation, and the morphological changes during the larval development of this species.

\section{MATERIAL AND METHODS}

Adult specimens of Pygospio elegans (Spionidae) were collected from the intertidal sandy flats at List/Sylt and maintained in the laboratory. Hatched larvae were reared at a salinity of $30 \%$, a temperature of $18^{\circ} \mathrm{C}$ and fed a mixture of Dunaliella sp. and Phaeodactylum sp. For transmission electron microscopy, different larval stages were first relaxed for $15 \mathrm{~min}$ in a $7 \% \mathrm{MgCl}_{2}$ solution. Fixation followed a modified simultaneous method used by Franke et al. (1969) in a solution of $2 \%$ glutaraldehyde and $1 \%$ $\mathrm{OsO}_{4}$ in $0.1 \mathrm{~m}$ cacodylate buffer $(\mathrm{pH} 7.4)$ for $1 \mathrm{~h}$ at $0^{\circ} \mathrm{C}$. Specimens were then rinsed in chilled buffer containing $7 \%$ succrose and $2.5 \mathrm{mM} \mathrm{CaCl}_{2,}$ and subsequently postfixed for $2 \mathrm{~h}$ at $0^{\circ} \mathrm{C}$ in $1 \% \mathrm{OsO}_{4}$ in the same buffer.

Larvae were dehydrated in an ethanol series and embedded in Durcupan. Serial sections were made with glass and diamond knives, stained with uranyl acetate and lead citrate and examined with a ZEISS EM 9S-2 electron microscope.

\section{RESULTS}

The comparative ultrastructure of larval nuchal organs is described, focussing on the hatching stage of Pygospio elegans, i.e. the 3-setiger larva and on a late larval stage just before metamorphosis with an average of 15 setigers.

\section{3-setiger larva}

\section{General morphology}

In newly hatched larvae, the paired nuchal organs are situated dorsolaterally in the posterior region of the prostomium, at the same level as the posterior portion of the brain 
between lateral ocelli and prototroch (Figs 1 and 3). The distance between the sensory structures of each side measures about $40 \mu \mathrm{m}$.

Each organ consists of two cell types only: bipolar primary sensory cells and supporting cells termed as ciliated cells.

The nuchal organs rest on a fine filamentous, monolayered basal lamina (Fig. 2); laterally, on the undersides of the ciliated cells, retractor muscles are anchored by hemidesmosomes to the basal lamina, and run in ventro-apical direction towards the prostomial musculature. The muscular insertion site of the basal lamina has twice the width $(0.2 \mu \mathrm{m}$ approx. $)$ of the usual dimensions. 5 to 6 ciliated cells form a monolayered, in surface view almost square ciliated area (up to $8 \mu \mathrm{m}$ in length and $9 \mu \mathrm{m}$ in width) that is continuous with the normal epidermis of the prostomium (Figs 1, 3, and 4).

About 15 sensory cell bodies constitute a nuchal ganglion, basally situated between ciliated cells and basal lamina (Fig. 4) that extends from the mediofrontal to the laterocaudal margin of the ciliated patch. The anterior pericarya are embedded in the ganglionic mass of the central nervous system (Fig. 5). The nuchal ganglion therefore is closely associated both with the sensory epithelium and with the posterior portion of the brain.

The anterior sensory neurons give rise to slender distal processes running diagonally upwards and outwards to the body surface. Consequently, a discrete sensory area made up of the clustered dendrites of the sensory cells, marks the mediofrontal margin of the ciliated region (Fig. 4). The posterior sensory cells do not yet show any differentiation of dendritic processes.

\section{Innervation}

As the nuchal ganglion is largely integrated into the central nervous system, a distinct nuchal nerve is lacking. Only an inconspicuous nerve is apparent (Fig. 6), comprising the axons of the remotest, caudally situated sensory cells. This nerve runs forward on the basal lamina to enter the posterior circumesophageal connective.

\section{Cuticle}

The structure of the cuticle overlying the nuchal organs differs to a certain degree from the cuticle of the other body wall (Fig. 7). The normal cuticle forms a moderately electron-dense, amorphous layer with an irregular arrangement of very fine filaments, measuring 0.6 to $0.8 \mu \mathrm{m}$ in depth. Occasionally branched microvilli of the epithelial cells pass through the cuticular matrix terminating as spherical bodies of high electron density above the cuticular surface.

In comparison, the nuchal cuticle, only $0.3 \mu \mathrm{m}$ in depth, is a very thin layer. Furthermore, the microvilli of the nuchal ciliated cells run through the cuticular layer to dilate into broad, irregularly shaped endings above the cuticular surface, forming a kind of outer cover about $0.3 \mu \mathrm{m}$ in depth. The exposed tips of these distended portions also appear as electron-dense spherical bodies. The distal ends of the microvilli measure up to $0.4 \mu \mathrm{m}$ in diameter and are closely joined together leaving interspaces of only $10 \mathrm{~nm}$ approx. (Fig. 8); the result is a closely meshed layer, penetrated only by the motile cilia of the ciliated cells. The centres of the microvilli contain a moderately electron-dense, flocculent material surrounded by a more electron-lucent peripheral zone.

The cuticle is underlaid with a distinct extracellular space, the olfactory chamber (Whittle \& Zahid, 1974) (Fig. 7). It measures about $8.5 \mu \mathrm{m}$ in diameter and $1.2 \mu \mathrm{m}$ in depth 

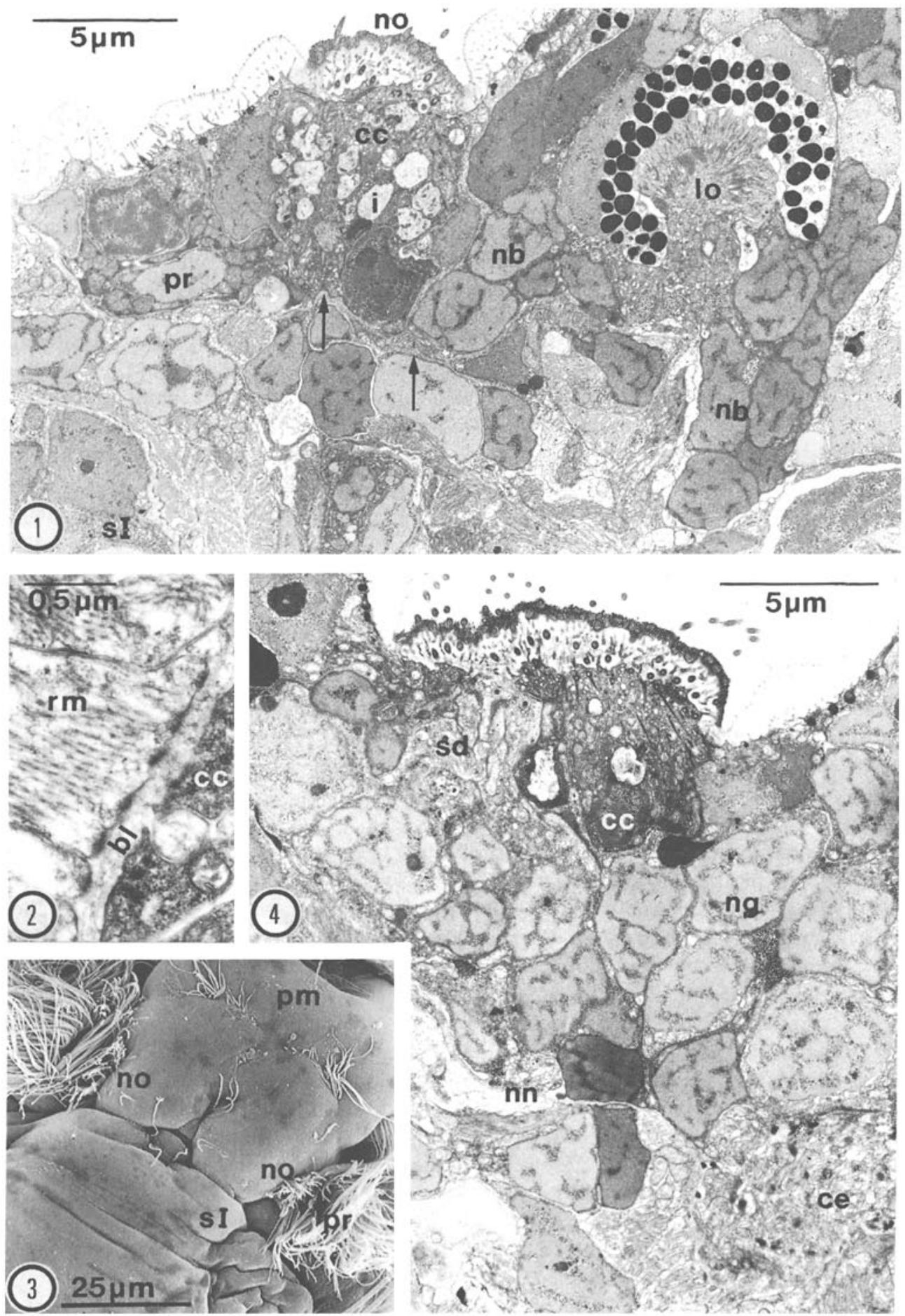

1920.

sd 5 of
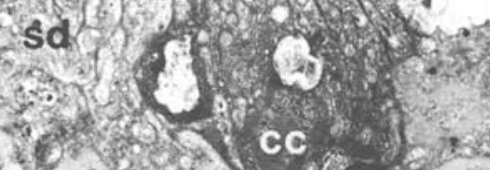

(1) $2 \times \frac{2}{3}$

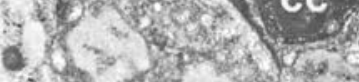
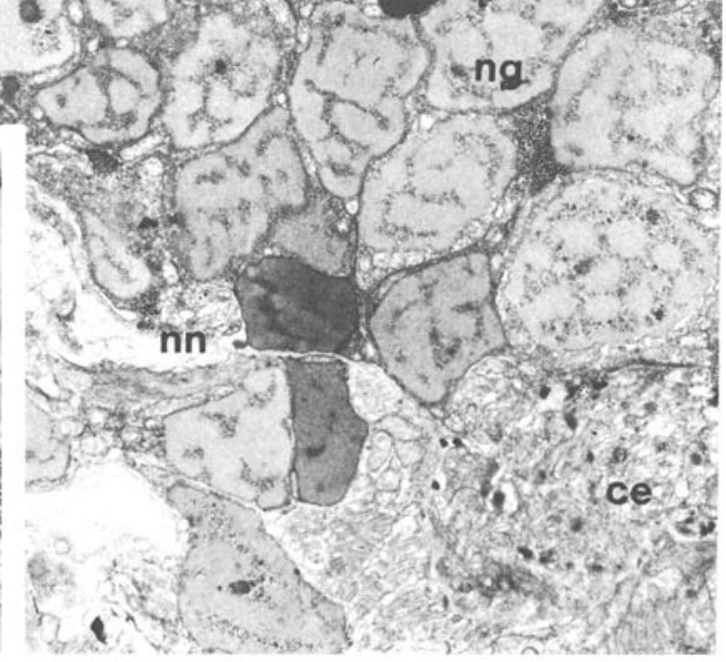
and is delineated anteriorly by the distal processes of the sensory cells and posteriorly by the apices of the ciliated cells. Horizontally, it is traversed by the microvilli and sensory cilia of the dendrites; vertically, by the microvilli and motile cilia of the ciliated cells.

\section{Ciliated cells}

The columnar supporting cells are arranged in a single-celled layer; laterally they rest on the basal lamina, medially they are underlaid with sensory cells. They measure up to $8.5 \mu \mathrm{m}$ in length and are joined apically by zonulae adherentes followed by long septate junctions. Their fine structure differs to a high degree from the cytoarchitecture of the normal surrounding epidermal cells. In general, the ciliated cells contrast by the electron-dense appearance of their cytoplasm, caused by large amounts of ribosomes freely distributed in the cytoplasm (Figs 9 and 13).

The apical cell surface is provided with a border of occasionally branched microvilli and a number of motile cilia showing the typical $9+2$-arrangement of the axoneme, basal feet and a pair of striated rootlets with a periodicity of $660 \AA$ approx. (Fig. 16). Accessory centrioles are lacking.

The apical cytoplasm shows a distinct concentration of small spherical vesicles up to $150 \mathrm{~nm}$ in diameter with electron-lucent contents (Fig. 9). Numerous small vesicular invaginations of the cell membrane (Fig. 10) indicate either a micropinocytotic uptake or extrusion of components.

Frequently in close proximity to the vesicles the cytoplasm contains multivesicular bodies up to $0.7 \mu \mathrm{m}$ in diameter. The incorporation of microvesicles into these bodies by invaginations of the limiting membrane may occasionally be observed (Fig. 11). The multivesicular bodies undergo a process of differentiation: electron-transparent bodies with only few vesicles and sparse fibrillar material gradually develop into bodies completely filled with clumps of diffuse fibrillar material, in which a number of doublemembrane-bound vesicles are scattered (Fig. 12).

Furthermore, mitochondria and a few lipid droplets are distributed between the ciliary rootlets and the vesicles.

Prominent components of the middle region are conspicuous, irregularly shaped, membrane-bound inclusions, which contain strands of fine filamentous material in

Abbreviations: bb basal body; bl basal lamina; c cuticle; $c c$ ciliated cell; ce circumesophageal connective; $c v$ clear vesicles; dv dense-core vesicles; er granular ER; $g$ golgi complex; i filamentous inclusion; l lipid droplet; ly lysosomes; mb multivesicular body; mc motile cilium; mi mitochondrium; $_{i} \mathrm{mv}_{\text {microvilli; }}$ nb neurons of the brain; ng nuchal ganglion; nn nuchal nerve; no nuchal organ; nu nucleus; oc olfactory chamber; pr prototroch; ps primary sensory cell; r rootlet; ri ribosomes; rm retractor muscle; sl setiger $I_{\text {; }}$ sb sensory bulb; sd sensory dendrite; ser smooth $\mathrm{ER}_{i}$ sj septate junction; $t$ neurotubules; za zonula adherens.

Figs 1-17. 3-setiger larva:

Fig. 1. Longitudinal section through posterior portion of prostomium showing the location of the nuchal organ (no) in relation to lateral ocellus (lo), neurons of the brain (nb), prototrochal cells, and the first setiger (sI). The section marks the lateral portion of the nuchal organ with the ciliated cells (cc) in direct contact with the basal lamina (arrows)

Fig. 2. Retractor muscles (m) insert into the basal lamina (bl) by hemidesmosomes on the undersides of the ciliated cells (cc)

Fig. 3. Scanning electron micrograph of the dorsal surface of the prostomium (pm)

Fig. 4. Cross section through the nuchal organ 

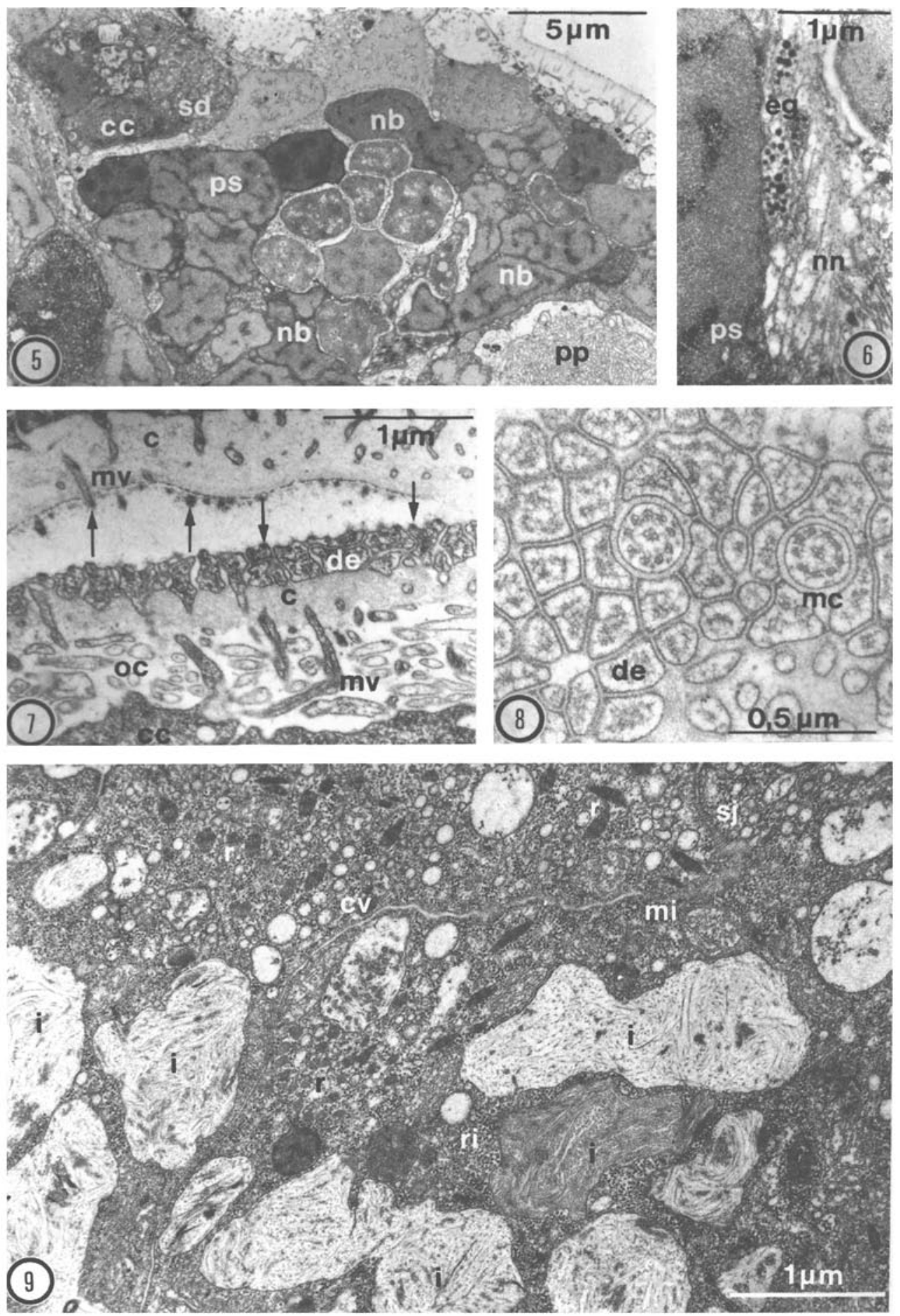
varying density (Figs 9 and 13). They occur in groups of smaller units in some cells, while in others they coalesce to form large, irregularly outlined vacuoles, occupying almost the entire middle region of the cell. The inclusions are often surrounded by few cisterns of granular ER, which starts to differentiate. A histochemical examination of the material is intended. A well developed Golgi-complex is generally located above the nuclear region and is associated with numerous clear vesicles.

The basal cytoplasm contains the large, irregularly shaped nucleus, which is elongated in the transverse axis of the cell, measuring about $3 \mu \mathrm{m}$ in length. It is characterized by extensive electron-dense clumps of chromatin and two compact nucleoli (Fig. 14).

\section{Sensory cells}

The pericarya of the bipolar primary sensory cells contain the nuclei with extensive, moderately electron-dense chromatine masses, mitochondria, Golgi-bodies, vesicles, granular ER, lipid droplets, and glycogen.

The bundled distal processes extend to the olfactory chamber. The terminal ends of the dendrites are enlarged forming sensory bulbs up to $1 \mu \mathrm{m}$ in diameter. The distal border of each bulb bears a single, modified sensory cilium and a few long microvilli that both traverse the olfactory chamber in its full length in caudal and lateral direction, intermingling with the motile cilia and microvilli of the ciliated cells (Figs 15 and 17). The microvilli (about $80 \mathrm{~nm}$ in diameter) show a clear central space and peripheral flocculent material of moderate electron-density sticking to the inner surface of the membrane.

The sensory cilia arise from the base of the invaginations of the outer surface. The axonemal filaments, arranged in a 9+2-pattern, are embedded in a homogenous, electron-dense matrix that fills the central lumen of the sensory cilia (Fig. 15). This matrix continues distally from the basal plate for about $0.5 \mu \mathrm{m}$, before the cilium splits up into several, up to nine microvillus-like structures with a diameter of about $90 \mathrm{~nm}$. While the central fibers end at the splitting point, each microvillous process contains at least one pair of axial filaments, that are, however, also lost after a short distance. The basal bodies of the modified cilia lack ciliary rootlets; an accessory centriol, arranged parallel to the cilia, is present. Sensory dendrites are joined apically by zonulae adherentes and below these by long septate junctions extending nearly over the total length of the processes.

The dendrite cytoplasm contains a number of clear (up to $120 \mathrm{~nm}$ ) and electrondense (up to $50 \mathrm{~nm}$ ) vesicles, neurotubules, mitochondria, a few multivesicular bodies, ribosomes and liped droplets.

Fig. 5. Longitudinal section through posterior portion of prostomium and the interior part of the nuchal organ; the cell bodies of the anterior sensory neurons lie within the central nervous system (anterior to the right); pp: presumed photoreceptor in the brain

Fig. 6. The nuchal nerve contains axon types with neurosecretory granules (eg)

Fig. 7. Section through the cuticle overlying the normal epidermal cells (top of figure) and the nuchal organ (bottom of figure); de: dilated ends of microvilli of ciliated cells; arrows: dense spherical bodies

Fig. 8. Horizontal section through the covering layer formed by the dilated ends (de) of the microvilli of the ciliated cells

Fig. 9. Cross section through ciliated cells 


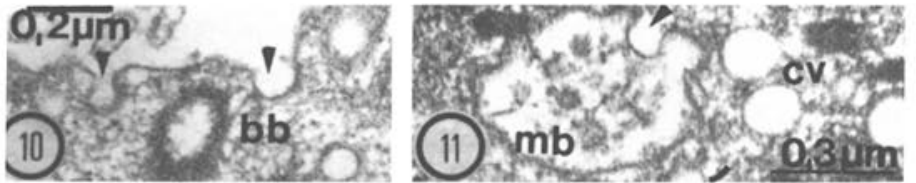
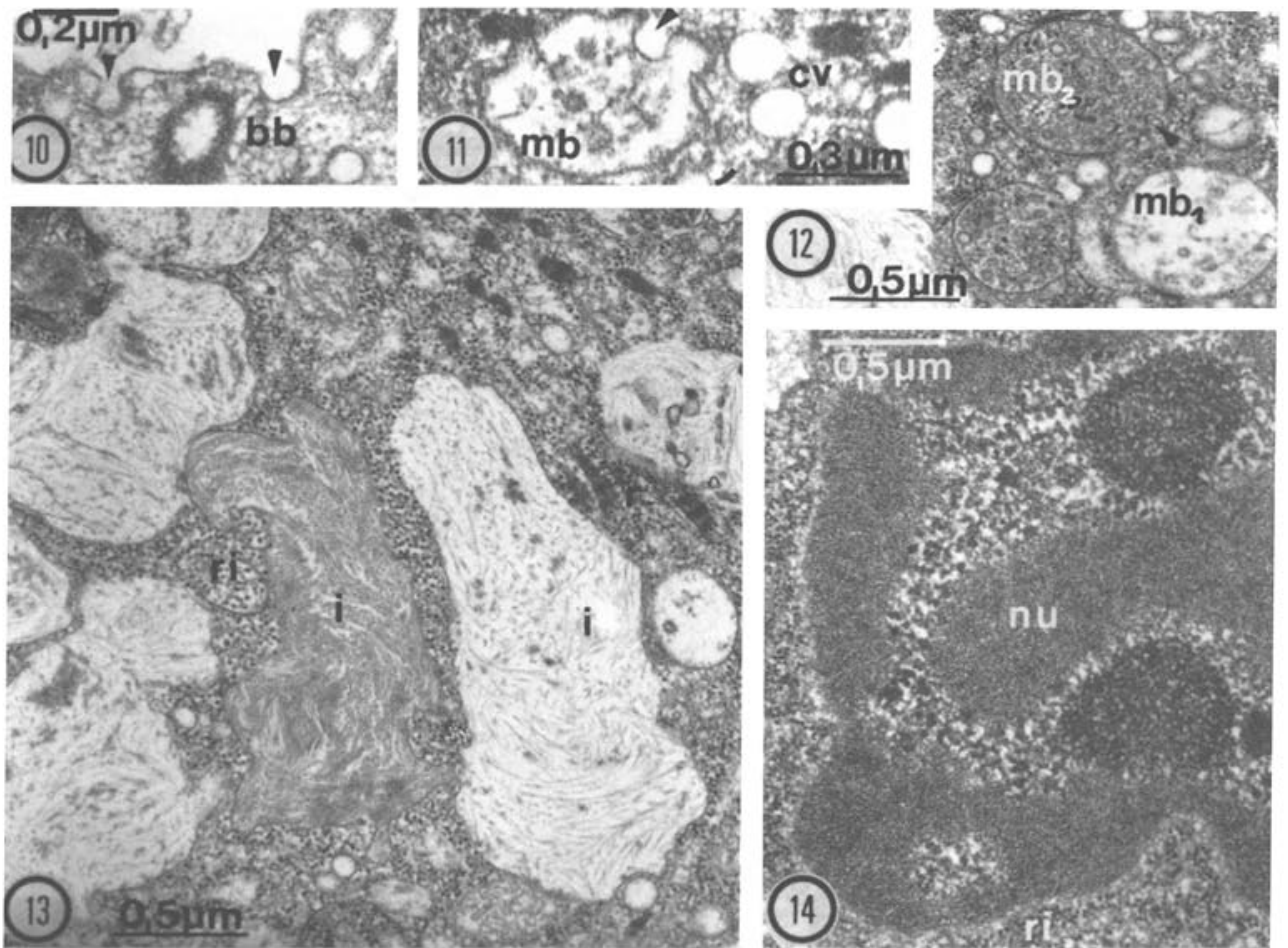

(12) $0,5 \mu \mathrm{m}, \mathrm{mb}_{2}=\mathrm{s}$
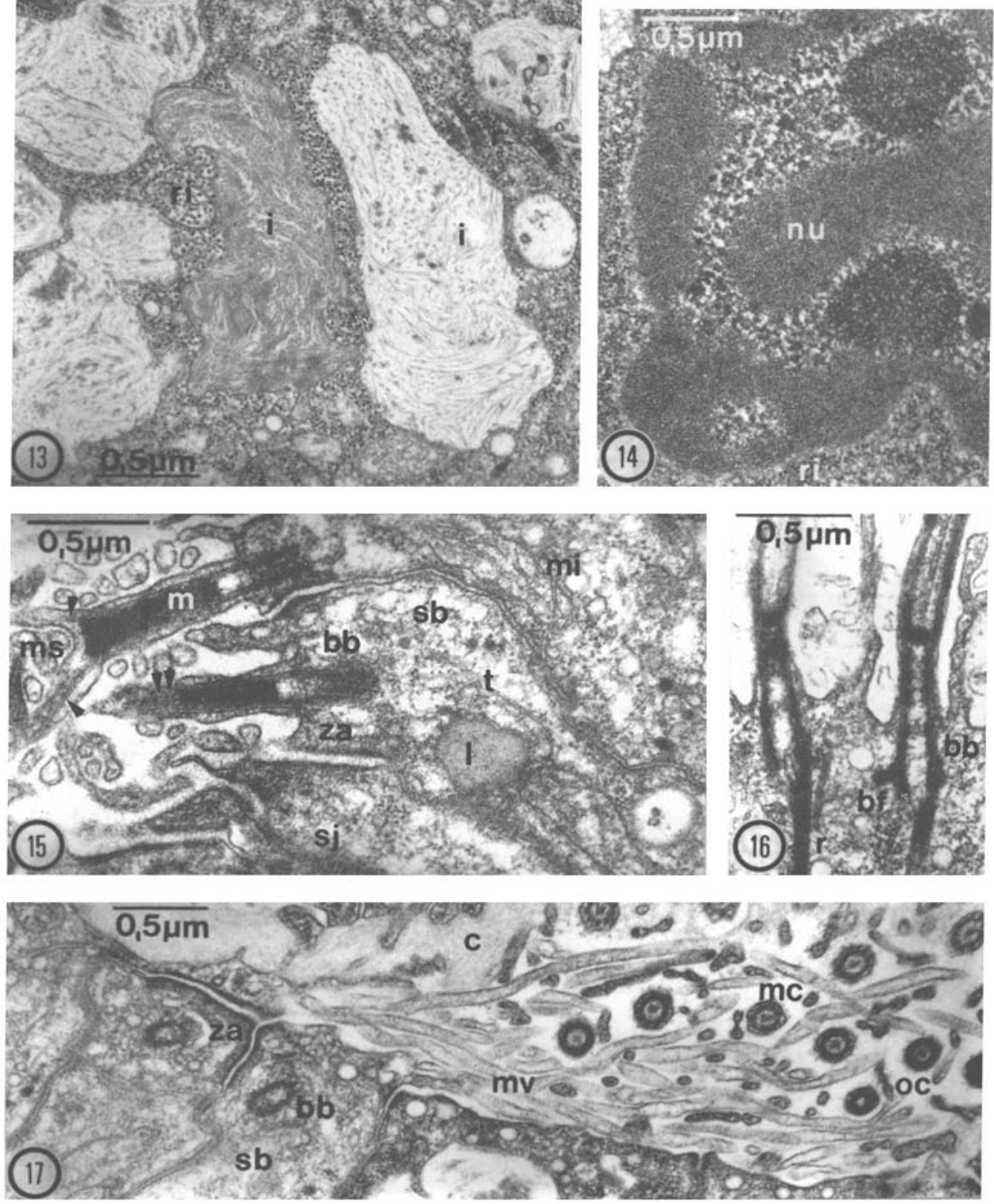


\section{5-setiger larva}

\section{General morphology}

The nuchal organs of late larval stages of Pygospio elegans extend from the posterior border of the prostomium behind the prototroch to the anterior margin of the first setiger. Consequently, a shift of position has taken place from the prostomium backwards into the metastomium (Figs 18 and 19). The sensory epithelia still border mediofrontally on the ganglionic mass of the posterior portion of the brain (Fig. 18).

Due to an additional slight shift from the initial dorsolateral position to a rather dorsal location, the sensory organs of each side delimit the developing medial nuchal crest or caruncle (Fig. 19); the distance between them measures 30 to $35 \mu \mathrm{m}$.

Furthermore, the nuchal organs are larger in size; the ciliated and sensory regions are expanded as a result of an increase in number of the ciliated and sensory cells as well as an increase in cell size.

9 to 12 ciliated cells form an oval-shaped ciliated area measuring up to $30 \mu \mathrm{m}$ in length and $23 \mu \mathrm{m}$ in width.

The sensory cells of the nuchal ganglion are clustered into 3 groups or centres, each related to a separate bundle of dendrites, thus forming 3 distinct sensory areas around the ciliated patch (Fig. 23). Nuchal centre I (Figs 21 and 23), representing the largest group of sensory cells, forms the mediofrontal boundary of the ciliated area; its cell bodies are completely integrated into the posterior portion of the central nervous system. No barrier of neuroglia or connective tissue separates the sensory cells from the neurons of the brain. The appertaining dendrites pass backwards parallel to the longitudinal axis of the larva to turn off at right angles towards the surface. Their microvilli and sensory cilia project backwards and outwards through the olfactory space, which covers the entire nuchal area.

The smallest nuchal centre II (Figs 22 and 23) marks the mediocaudal border of the ciliated region. In the same way, the dendritic processes run forward parallel to the longitudinal axis and terminate in the olfactory chamber.

Nuchal centre III (Figs 20 and 23) is situated laterally at the posterior edge of the ciliated area, extending backwards to the level of the setal sac of the first setiger. The distal processes of the neurons run vertically upwards to the body surface; the dendritic microvilli and sensory cilia traverse the olfactory chamber in anterior direction.

The 3 groups of sensory cells are connected by a few basally located neurons.

Fig. 10. A detail of the apical membrane of ciliated cells showing slight invaginations (arrows)

Fig. 11. Multivesicular bodies incorporate vesicles by invaginations of their limiting membrane (arrow)

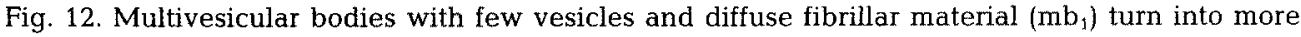
condensed stages with an increased number of vesicles $\left(\mathrm{mb}_{2}\right)$; arrow: membrane invagination

Fig. 13. Middle region of ciliated cell

Fig. 14. Basal region of ciliated cell with part of the nucleus

Fig. 15. Sensory bulbs with sensory cilia; the cilia split up into several microvillus-like structures (ms), each containing one pair of microtubuli (arrows); the central microtubuli (double arrow) end at the splitting point; $m$ : electron-dense matrix

Fig. 16. The basal bodies of the motile cilia possess basal feet (bf) and striated rootlets

Fig. 17. Cross section through anterior portion of olfactory chamber showing the long sensory microvilli 

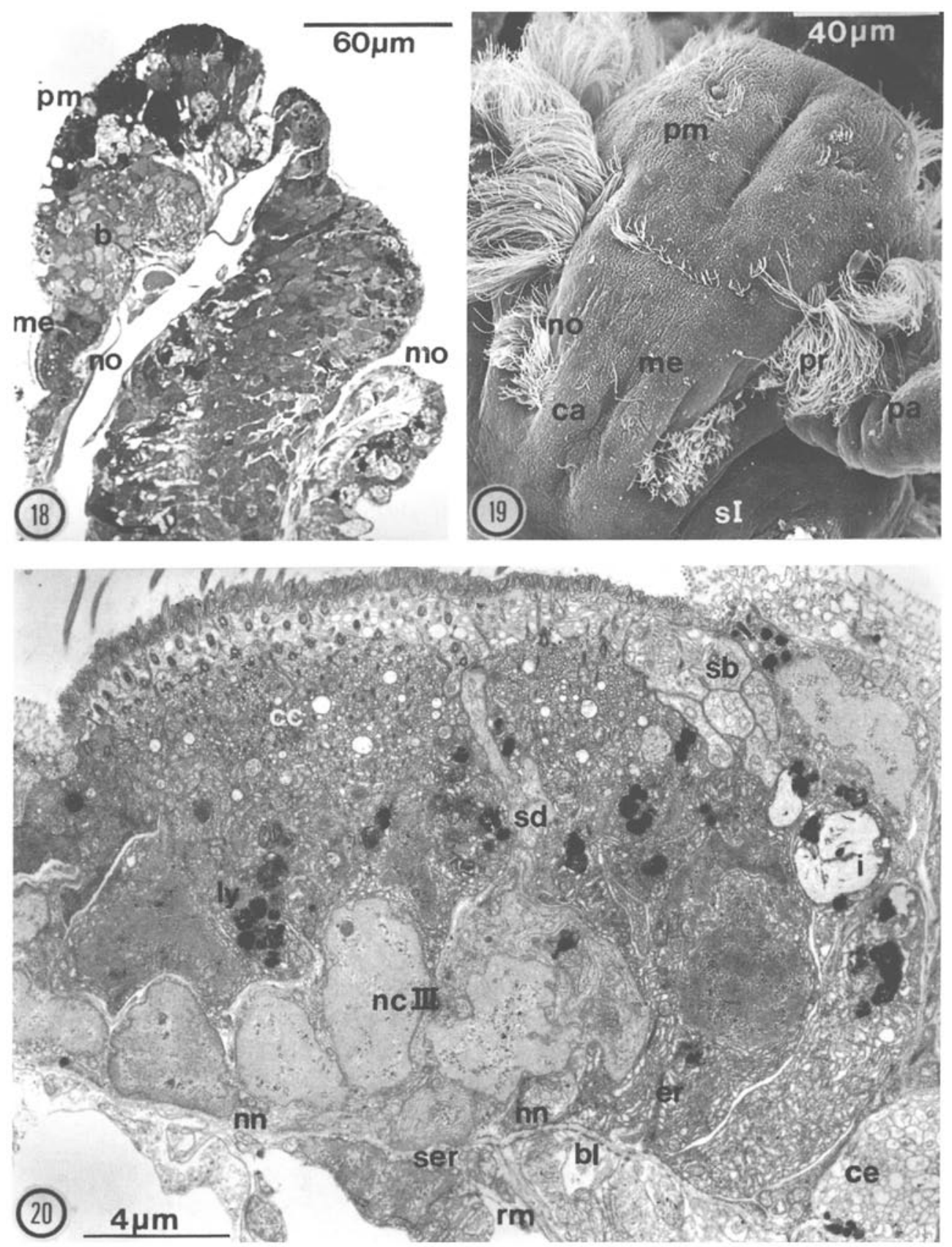

Figs 18-32. 15-setiger larva:

Fig. 18. Photomicrograph of a longitudinal section through the anterior body region; b: brain, me: metastomium, mo: mouth, pm: prostomium

Fig. 19. Scanning electron micrograph of the dorsal surface of the head region; pa: palps, ca: caruncle

Fig. 20. Nuchal centre III (nc III), longitudinal section; $\mathrm{mn}$ : outer nuchal nerve 

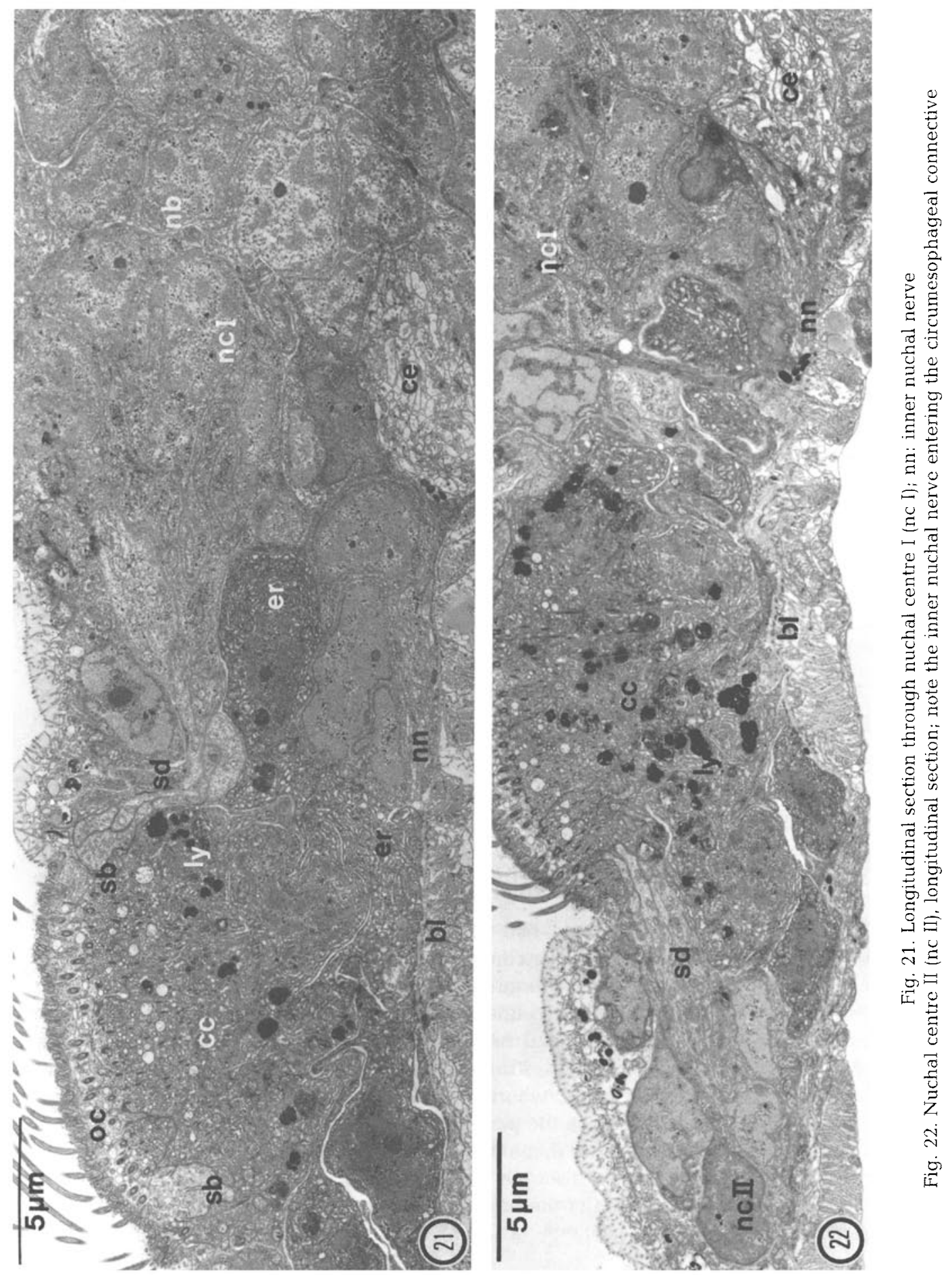


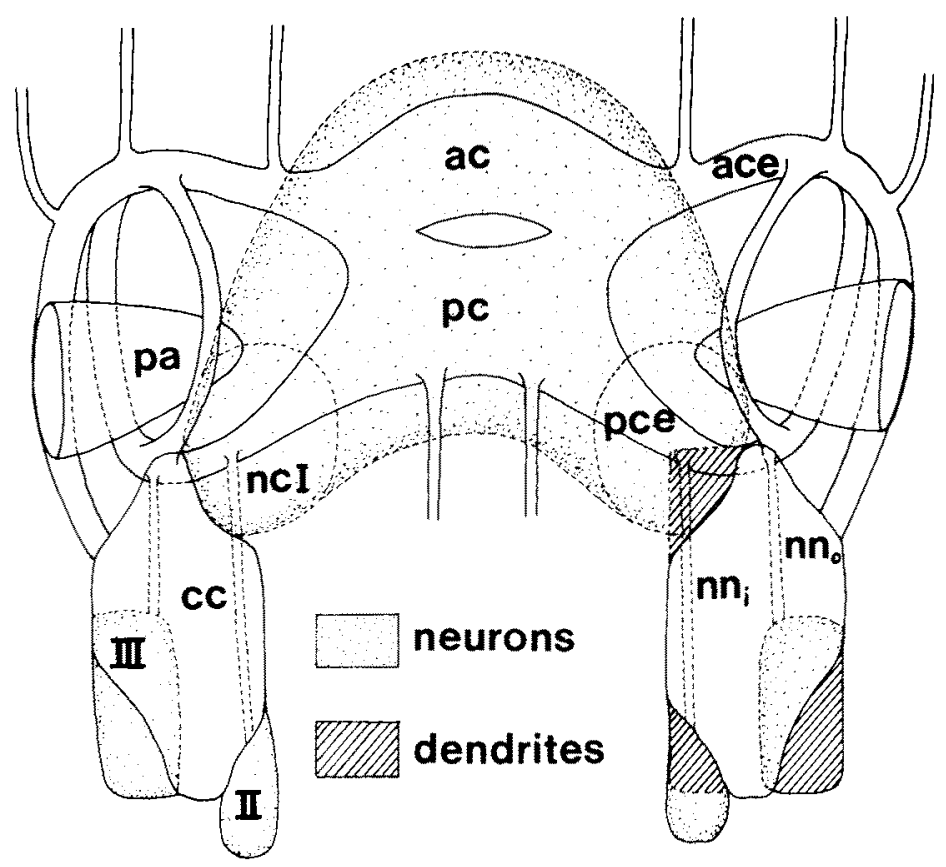

Fig. 23. Schematic reconstruction of the nuchal organ of a 15-setiger stage in relation to the central nervous system in dorsal view; ac: anterior commissure of the brain, ace: anterior circumesophageal connective, $\mathrm{nc}$ I-III: nuchal centres I-III, $\mathrm{nn}_{\mathrm{i}}$ : inner nuchal nerve, $\mathrm{nn}_{\mathrm{o}}$ : outer nuchal nerve, pa: palp, pc: posterior commissure of the brain, pce: posterior circumesophageal connective

The undivided nuchal ganglion of the 3-setiger larva consequently differentiates into 3 coherent nuchal centres; the sensory area of the 3-setiger larva corresponds to the nuchal centre I, while the caudal sensory cells of the hatched stage develop dendrites and are organized into the nuchal centres II and III, thus forming two additional sensory areas at the posterior end of the nuchal organs.

\section{Innervation}

Each nuchal complex reveals two nuchal nerves entering the posterior circumesophageal connective. The latter runs from the posterior commissure of the brain around the base of the palps to fuse ventrolaterally with the anterior circumesophageal connective (Fig. 23). As the posterior connective passes below the anterior portion of the sensory epithelium, only short nuchal nerves are apparent. The outer nuchal nerve comprises the axons of nuchal centre III (Fig. 20) and runs forwards to merge with the posterior connective at that point, where a curved nerve coming from the anterior circumesophageal connective joins the posterior one.

The axons of the nuchal centre II, making up the inner nuchal nerve (Figs 21 and 22), enter the posterior connective within the region of the nuchal centre I just before the connective joins the neuropilem of the brain. 


\section{Ciliated cells}

In the nuchal organs of late larvae the ciliated cells have increased in size, now measuring up to $15 \mu \mathrm{m}$ in length. Adjacent cells are often connected by lateral membrane interdigitations. During the post-embryonic development the following ultrastructural changes occur: The amount of free ribosomes is considerably reduced, causing a more electron-transparent appearance of the cytoplasm (Fig. 24). Instead, extensive profiles of granular ER are differentiated in the basal regions of the cells (Figs 20, 21 and $24)$, concentrically arranged around the nucleus. The partly distended cisternae contain a fine flocculent material of low electron-density and are in close contact with the Golgizones (Figs 25 and 26).

The depots of the large, filamentous material containing inclusions have almost entirely disappeared. The few remaining inclusions are always closely associated with granular ER, Golgi-zones, dense-core vesicles, and numerous conspicuous dense bodies resembling lysosomes (Fig. 26), the number of which proportionally increases with the catabolism of the filamentous material. Transitory stages between the filamentous and the dense bodies are frequently observed (Figs 24 and 28). These supposed lysosomes are roughly spherical bodies, showing varying degrees of differentiation: they contain moderately electron-dense fibrous and flocculent material, myelin-like membrane configurations, vesicular elements, and few clumps of electron-dense material up to increasingly condensed inclusions (Figs 27 and 28); they are abundant in the supranuclear cytoplasm, always surrounded by numerous well-developed Golgi-complexes. The Golgi-zones are associated both with small clear vesicles and with larger dense-core vesicles with a max. diameter of $250 \mathrm{~nm}$ and a punctate core (Figs 27 and 28). While the dense-core vesicles are largely found in the middle region of the cells, the heavily increased clear vesicles accumulate in the apical cytoplasm, varying in diameter from 60 to $320 \mathrm{~nm}$. Multivesicular bodies are more numerous and scattered throughout the cytoplasm (Fig. 24).

\section{Sensory cells}

The fine structure of the sensory cells differs regarding the several nuchal centres: the sensory neurons of the nuchal centre III are characterized by extensively developed cisterns of the smooth ER, concentrically arranged around the nucleus or concentrations of electron-dense particles (Figs 20 and 30). Whirls formed by the smooth ER are frequent structures in these sensory cells. The single particles show an average diameter of $10 \mathrm{~nm}$ and are presumed to be ribosomes, the rosette-like aggregations measure up to $100 \mathrm{~nm}$ in diameter and it remains uncertain whether they represent polysomes or $\alpha$-glycogen particles. The agranular ER partly passes into granular cisterns (Fig. 30). Furthermore, the cytoplasm contains one supranuclear Golgi-complex associated with some clear vesicles (about $50 \mathrm{~nm}$ ), few larger vesicles with an electron-dense core (about $250 \mathrm{~nm}$ ), a number of mitochondria, free ribosomes, and occasional lysosomes. The prominent features of the sensory cells of the nuchal centre I are abundant small membrane-bound vesicles with a max. diameter of $60 \mathrm{~nm}$ representing neurosecretory granules of two different types: vesicles with electron-transparent and electron-dense contents (Figs 21 and 29). They are distributed throughout the cytoplasm with exception of the dendrites. The pericarya show the ultrastructural characteristics of peptide-secreting neurosecretory cells: a well-developed granular ER and Golgi-complex, mitochondria, multivesicular bodies, and free ribosomes. 


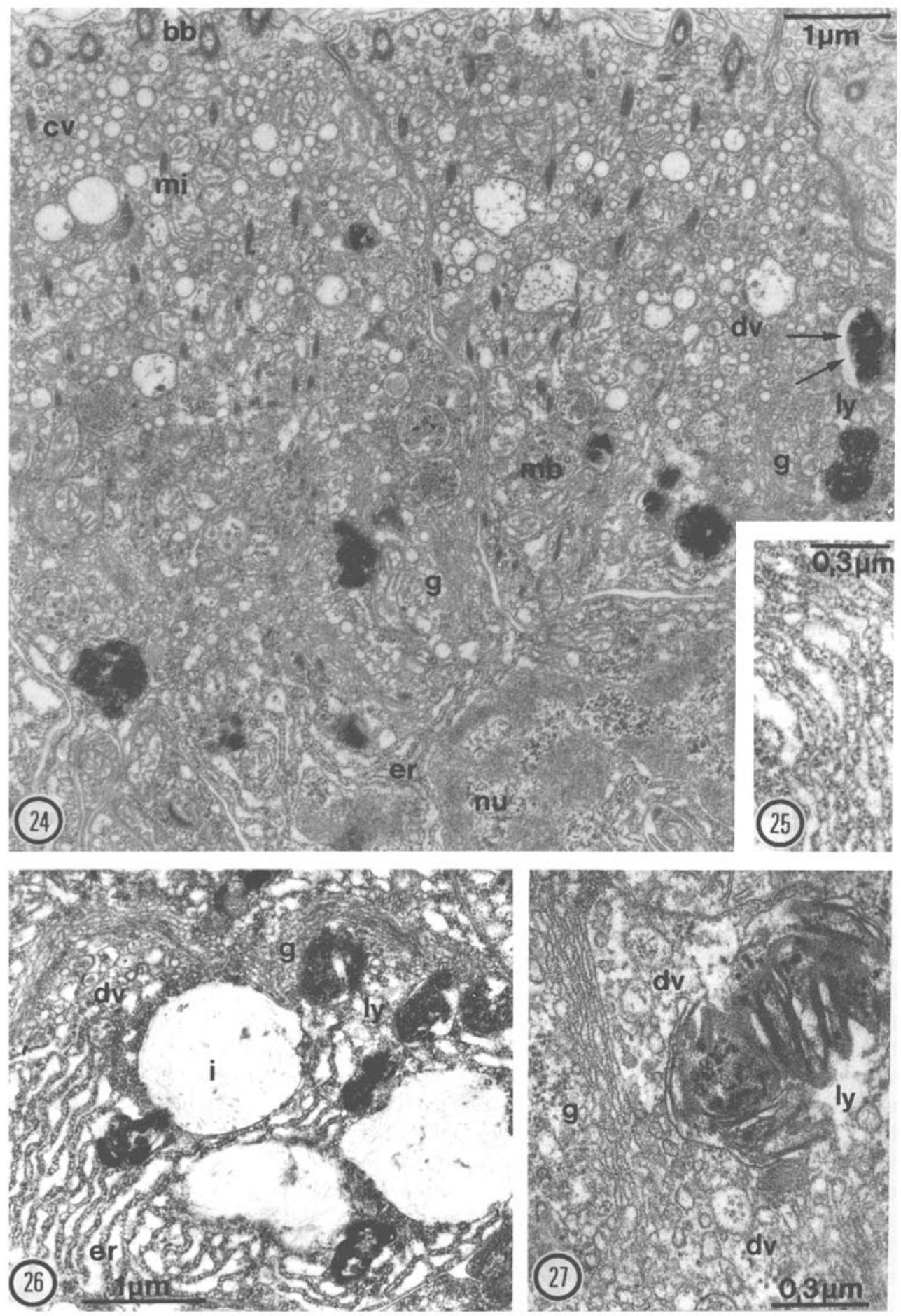


The distal dendrites of all sensory cells terminate in the olfactory chamber forming sensory bulbs and contain the same kinds of elements as in the young larvae. However, the membranes of the sensory cilia reveal considerable enlargements of their surface area by the development of dilated portions along their length and at their ends (Figs 31 and 32).

The axons of the sensory cells comprise the nuchal nerves; the axoplasm contains mitochondria, vesicles, neurotubuli, and ribosomes.

\section{DISCUSSION}

\section{Morphological changes}

The present study demonstrates the origin of the nuchal organs of Pygospio elegans in dorsolateral portions of the posterior part of the brain. The sensory neurons are primarily integrated into the central nervous system and secondarily joined to the sensory epithelia. Thus, the rudiments of the nuchal organs prove to be definitely prostomial or presegmental. The results, therefore, confirm the embryological studies of Ákesson in Eunice kobiensis (1967a) and Lopadorhynchus (1967b), but refute Söderström's (1920; 1930) and Rullier's (1951) statements that sedentary polychaetes do not possess any embryological connection between nuchal organs and the brain. The incorporation of the nuchal ganglion into the brain, therefore, does not represent the derived but the primary condition in spionid polychaetes.

The morphological changes which occur during development include a general increase in size accompanied by a shift in position, an expansion of the ciliated and the sensory areas, as well as changes in the ultrastructural features of the cells.

The shift in position from the prostomium backwards into the metastomium is due to a slight caudal extension of the prostomium resulting in a caudal displacement of the brain. The shift from dorsolateral to dorsal may be explained by differential growth or cell movement giving rise to the medial nuchal crest.

Expansion of the ciliated area is a result of a general increase in cell size and an addition of cells; the expansion of the sensory area is caused by an increase in number of sensory cells and the differentiation of two additional nuchal centres at the posterior margin of the nuchal organs, resulting in three distinct sensory areas. The partial detachment of the nuchal centres II and III from the brain during development requires two nuchal nerves entering the posterior circumesophageal connective.

The change of ultrastructural features of the ciliated cells is related to increasing secretory activity. The ciliated cells of 3-setiger larvae are characterized by large amounts of ribosomes, freely distributed in the cytoplasm. On the other hand, the cells contain an only weakly developed granular ER. Ribosomes, not associated with membranes, are abundant organelles of developing cells and responsible for the production

Fig. 24. Cross section of ciliated cells; arrows: transitory stage between filamentous and residual body

Fig. 25. A detail of the partly dilated cisterns of the granular ER containing fine fibrillar material Fig. 26. The filamentous inclusions are closely associated with granular ER, Golgi-zones, densecore vesicles, and lysosomes

Fig. 27. A detail of the middle region of a ciliated cell 

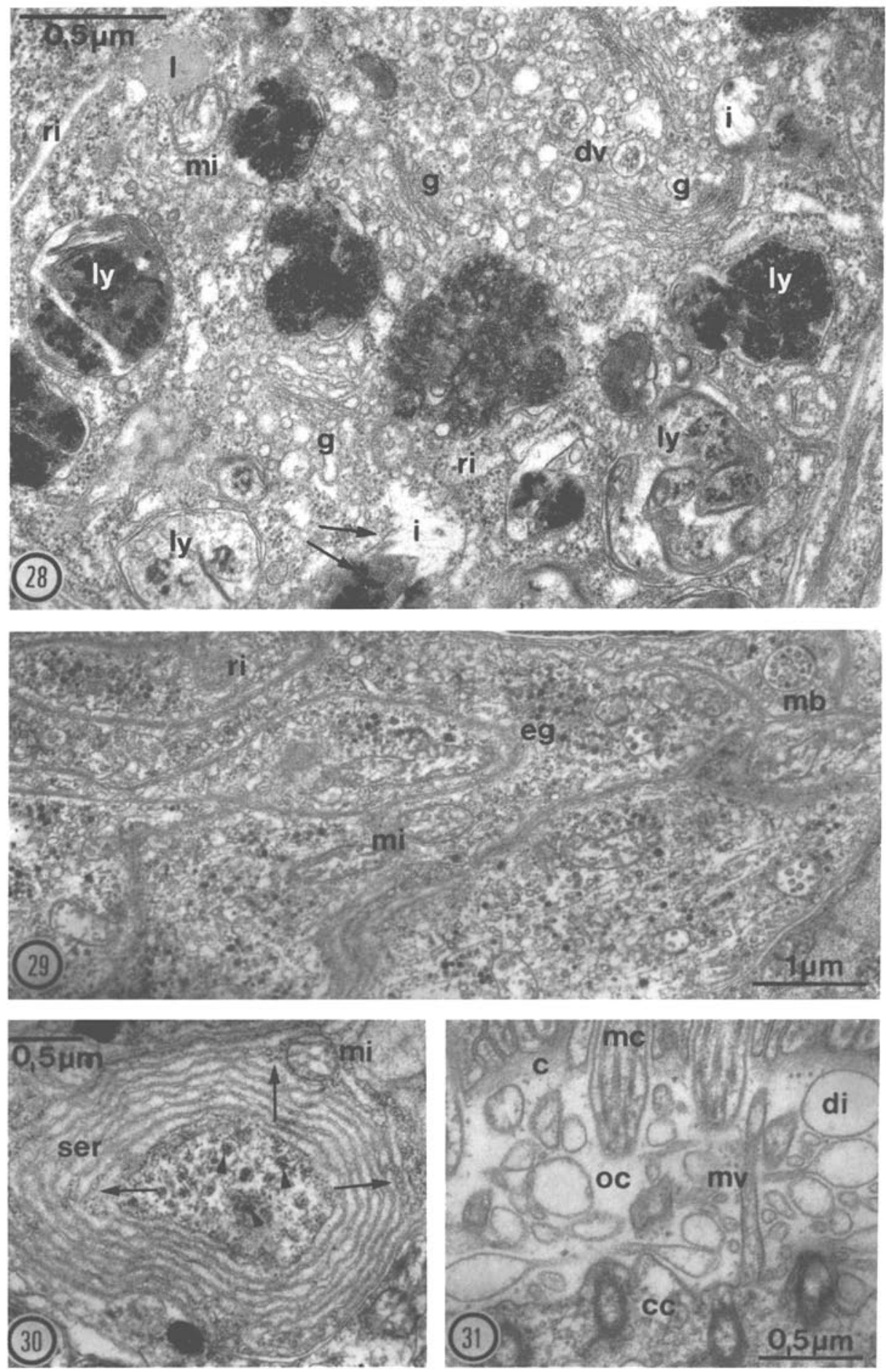


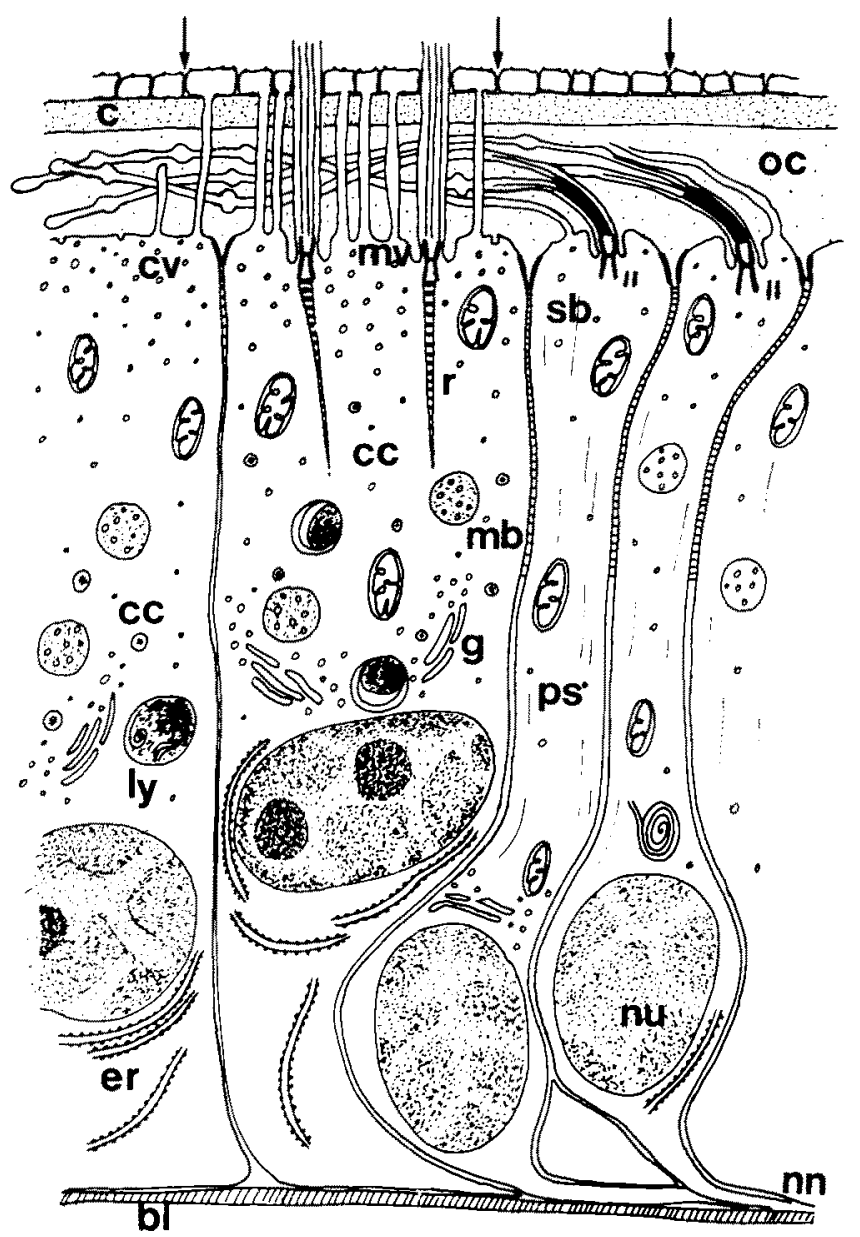

Fig. 32. Schematic longitudinal section through part of nuchal organ

of proteins needed for growth. As the cells increase in size the amount of free ribosomes considerably decreases in favour of the differentiation of an extensive granular ER. Simultaneously, the depots of the large inclusions containing filamentous material vanish, while the number of dense, Iysosome-like bodies increases proportionally. The inclusions are supposed to contain material which is released by fusion with primary lysosomes to be involved in the differentiation process of cell, probably in secretory

Fig. 28. The middle region of ciliated cells is characterized by accumulations of lysosomes in various degrees of differentiation in the vicinity of several secreting Golgi-zones; arrows: transitory stage between filamentous and residual body

Fig. 29. Sensory neurons of nuchal centre I containing clear and dense neurosecretory granules (eg) Fig. 30. Detail of a sensory neuron of nuchal centre III, showing whirls formed by the smooth ER, which partly passes into granular cisterns (arrows); arrow-heads: rosette-like aggregations of particles

Fig. 31. Detail of the olfactory chamber showing partial dilations (di) of the sensory cilia 
activity. There is no evidence that the filamentous contents are released from the cell surface.

The differentiated ciliated cells show typical cytological features indicating an intensive synthesis of proteinous secretory products (Bubel, 1983): two large, compact nucleoli, a massive granular ER, several well-developed Golgi-zones producing clear and dense-core vesicles, a number of multivesicular bodies, as well as abundant autophagosomes and residual bodies; their number is related to the degree of secretory activity. The secretory products are probably formed in the partly distended cisterns of the ER, and concentrated and vesiculated by the Golgi-complex. The secretory vesicles migrate and accumulate in the apical cytoplasm, and partly enlarge their size by amalgamations, before being finally released across the apical cell membrane into the extracellular space in which the sensory structures are embedded.

The prominent morphological changes of the sensory cells refer to the differentiation of concentrically arranged cisterns of the smooth ER in sensory neurons of the nuchal centre III, and to the accumulation of neurosecretory granules in the cells of the nuchal centre I. Lamellae and whirls formed by the agranular ER are, according to Bullock \& Horridge (1965), frequent structures in invertebrate sensory neurons.

The involvement of neurosecretory elements in invertebrate sensory structures has often been reported. Dhainaut-Courtois (1968) and Golding (1973) pointed out that, in some polychaetes, presumed photoreceptors embedded in the brain are associated with neurosecretory centres, possibly playing a role in the control of neuroendocrine function. Merker \& Vaupel-von Harnack (1967) found the maximum concentration of neurosecretory cells in the dorsolateral regions of the hindbrain of Protodrilus rubropharyngaeus, in close proximity to the nuchal organs. Furthermore, neurons resembling neurosecretory cells are constituents of the nuchal nucleus in Nereis pelagica (Dhainaut-Courtois, 1968). In Nephtys caeca (Whittle \& Zahid, 1974), neurosecretory elements occur in the nuchal nerves, which are possibly concerned with the control of ciliary activity. In the nuchal organs of Pygospio elegans, a part of the primary sensory cells itself shows a neurosecretory activity probably involved in mediating environmental influences. Besides, the larvae possess presumed photoreceptors embedded in the brain, which are also connected with secretory active primary sensory cells (Schlötzer-Schrehardt, in prep.). Possibly, both light and chemical stimuli affect the neurosecretory activity of the sensory cells; their axons can be traced back into the ventral neuropilem of the brain, which is lined by a coelomic space into which the secretory products are possibly released. The physiological effects in the organism, in which these systems are involved, have yet to be elucidated. Finally, the membranes of the sensory cilia in late larval stages develop a considerable enhancement of the surface area by dilations indicating an increase of the available sensory area.

As these morphological differentiations occur just before the beginning of metamorphosis, the nuchal organs perhaps play a role in the selection of the appropriate habitat during settlement.

\section{Comparative morphology}

On comparing the present study with previous ultrastructural investigations of adult polychaete nuchal organs, some basic conformities become obvious: the nuchal organs, located in the posterior region of the prostomium, always comprise retractor muscles, 
ciliated cells, and bipolar primary sensory cells forming the nuchal ganglion (except the secondary sensory cells in Eurythoe complanata described by Storch \& Welsch, 1969).

A common characteristic feature is an extracellular space, the olfactory chamber, extending between the cuticle and sensory epithelium. The sensory dendrites bear few microvilli and one (West, 1978) or several (Whittle \& Zahid, 1974) modified sensory cilia projecting into the chamber. The sensory cilia show the $9+2$-arrangement of the axoneme and taper into microvillus-like structures; the ciliary membrane forms coils or dilations achieving a considerable increase in the surface area.

Variations arise from the position of the nuchal ganglion; this is either associated with the sensory epithelium (Eulalia, Nephtys) or located within the posterior portion of the brain Nereis, Glycera, Ophelia). Consequently, the nuchal nerves either comprise the axons or the dendrites of the sensory neurons.

The arrangement of the larval nuchal organs of Pygospio elegans shows an intermediate stage. Due to the close proximity of the organs to the brain, they are both associated with the sensory epithelium and the cerebral ganglion, representing no doubt a primitive condition. The nuchal nerves are made up by the sensory axons.

Further differences are related to the cellular composition and arrangement. Ciliated and sensory cells either form discrete areas (West, 1978) as in P. elegans or the dendrites regularly separate the ciliated cells (Whittle \& Zahid, 1974). Additional cellular elements occur as supportive cells (Storch \& Welsch, 1969; West, 1978), presumable photoreceptor cells (Storch \& Welsch, 1969), and mucous glandular cells (Storch \& Welsch, 1969; Whittle \& Zahid, 1974).

\section{Functional morphology}

According to Rullier (1951) and Clark (1969), polychaete nuchal organs have combined secretory and sensory functions with different cells specialized for both activities. Although the larval muchal organs of $P$. elegans are confined to ciliated and sensory cells, the results confirm this statement, since the ciliated cells demonstrate an intensive secretory activity as pointed out above. Summarizing, the ciliated cells show three main functions: they bear the motile cilia; they give rise to protective structures over the sensory epithelium, and they secrete material surrounding the sensory elements (Fig. 32).

Previous authors supposed a chemoreceptive function of the nuchal organs particularly in terms of structural analogies to the vertebrate olfactory mucosa (Whittle \& Zahid, 1974; West, 1978). According to Laverack (1968, 1974) and Altner \& Prillinger (1980), chemoreceptors should be easily accessible to stimuli in the medium and expose a large surface area to them, but should also be protected from abrasion. Structural adaptions of the nuchal organs to these basic requirements are:

(a) The nuchal organs are located in the anterior body region. (b) The protective function of the cuticle is possibly enhanced by the microvillar cover overlying the nuchal area; it might mechanically stabilize the sensory epithelium. (c) The interspaces between these projections and the relatively thin cuticle allow the infiltration of the stimulus molecules. (d) The action of the motile cilia of the ciliated cells is responsible for generating water currents. (e) The olfactory chamber on the one hand ensures the circulation of the ambient medium and the exposure to the stimuli, and on the other hand 
protects the sensory structures against injury. (f) The modified sensory cilia, assumed to represent the receptive structures, display surface enlargement of the ciliary membranes by branching and dilating, thus increasing the available sensory area. $(\mathrm{g})$ The sensory endings are embedded within the secretion of the ciliated cells; Laverack $(1968,1974)$ suggests that the extracellular fluid surrounding the sensory cilia provides an ambient medium or a buffer between the receptor structures and the external environment, perhaps acting as a stimulus-conducting material.

In addition, the nuchal organs exhibit structural parallels to arthropod olfactory sensilla (compare Barber, 1974; Altner \& Prillinger, 1980); their chemoreceptor function is evidenced by physiological experiments: (a) Each chemoreceptor unit consists of bipolar primary sensory cells and supporting cells. (b) The sensory cells possess distal processes, which bear a modified cilium (= outer dendritic segment). (c) The ciliary membranes show an increase of the surface area by branching of the cilium; each branch contains at least one microtubule. (d) The ciliary processes pass into a liquid-filled extracellular space beneath the cuticle; the supporting cells are responsible for secreting the liquid and for the production of cuticular protective structures.

In conclusion, it is reasonable to assume that nuchal organs in fact are chemosensitive. A final definition of function, of course, has to wait until physiological evidence is available. An exact morphological study, however, can supply the fundamental structural preconditions and valuable indications.

Acknowledgements. The author is indebted to Prof. Dr. R. Siewing (Erlangen) for support and helpful discussion, and to Prof. Dr. V. Storch (Heidelberg) for critically reading the manuscript. The author would like to thank the Marine Station Helgoland for providing laboratory facilities, especially Mr. M. Sturm (List/Sylt) for assistance in collecting the material. Thanks are also due to Mrs. Ch. Trommer (Erlangen) for technical assistance.

\section{LITERATURE CITED}

Ákesson, B., 1967a. The embryology of the polychaete Eunice kobiensis. - Acta zool., Stockh. 48, $142-192$.

Ákesson, B., 1967b. On the nervous system of the Lopadorhynchus larva (Polychaeta). - Ark. Zool. $20,55-78$.

Altner, H. \& Prillinger, L., 1980. Ultrastructure of invertrebrate chemo-, thermo-, and hygroreceptors and its functional significance. - Int. Rev. Cytol. 67, 69-140.

Barber, V. C., 1974. Cilia in sense organs. In: Cilia and flagella. Ed. by M. A. Sleigh. Acad. Press, London, 403-433.

Bubel, A., 1983. A transmission and scanning electron microscopy study of the cuticle and epidermis of Pomatoceros lamarckii (Polychaeta: Serpulidae). - Trans. zool. Soc. Lond. 36, $217-268$.

Bullock, T. H. \& Horridge, G. A., 1965. Structure and function in the nervous system of invertebrates. Freemann, San Francisco 1, 1-750.

Clark, R. B., 1969. Systematics and phylogeny: Annelida, Echiura, Sipunculida - Chem. Zool. 4, 14.

Dhainaut-Courtois, N., 1968. Étude histologique et ulstrastructurale des cellules nerveuses du ganglion cérébral de Nereis pelagica L. (Annélide, Polychète). - Gen. comp. Endocr. 11, $414-443$.

Franke, W. W., Krien, S. \& Brown, R. M. jr., 1969. Simultaneous glutaraldehyde-osmium tetroxide fixation with postosmication. - Histochemie 19, 162-164.

Golding, D. W., 1973. Neuroendocrine phenomena in aphroditid and related polychaetes. 1 . The morphology and cytology of the infracerebral gland and cerebral neurosecretory system. - Acta zool, Stockh. 54, 101-120. 
Gustafson, G., 1930. Anatomische Studien über die Polychaetenfamilien Amphinomidae und Euphrosynidae. - Zool. Bidr. Uppsala 12, 305-471.

Korn, H., 1982. Annelida. Morphogenese der Tiere. Fischer, Stuttgart, 166 pp.

Laverack, M. S., 1968. On the receptors of marine invertebrates. - Oceanogr. mar. Biol. 6, 249-324.

Laverack, M. S., 1974. The structure and function of chemoreceptor cells. In: Chemoreception in marine organisms. Ed. by P. T. Grant \& A. M. Mackie. Acad. Press, London, 48 pp.

Merker, G. \& Vaupel-von Harnack, M., 1967. Zur Feinstruktur des "Gehirns" und der Sinnesorgane von Protodrilus rubropharyngaeus Jaegersten (Archiannelida), - Z. Zellforsch. mikrosk. Anat. $81,221-239$.

Rullier, F., 1950. Rôle de l'organe nucal des annélides polychètes. - Bull. Soc. zool. Fr. 75, 18-24.

Rullier, F., 1951. Étude morphologique, histologique et physiologique de l'organe nucal chez les annélides polychètes sédentaires. - Annls Inst. océanogr. Monaco 25, 207-341.

Söderström, A., 1920. Studien über die Polychätenfamilie Spionidae. Diss., Univ. Uppsala, 101 pp.

Soderström, A., 1930. Uber segmental wiederholte Nuchalorgane bei Polychäten. - Zool. Bidr. Uppsala 12, 1-25.

Storch, V. \& Welsch, U., 1969. Zur Feinstruktur des Nuchalorgans von Eurythoe complanata (Pallas), (Amphinomidae, Polychaeta). - Z. Zellforsch. mikrosk. Anat. 100, 411-420.

West, D. L., 1978. Comparative ultrastructure of juvenile and adult nuchal organs of an annelid (Polychaeta: Opheliidae). - Tissue \& Cell 10, 243-257.

Whittle, A. C. \& Zahid, Z. R., 1974. Fine structure of nuchal organs in some errant polychaetous annelids. - J. Morph. 144, 167-184. 